\title{
FORECASTING SURFACE WATER LEVEL FLUCTUATIONS OF LAKE SERWY (NORTHEASTERN POLAND) BY ARTIFICIAL NEURAL NETWORKS AND MULTIPLE LINEAR REGRESSION
}

\author{
Adam PIASECKI ${ }^{\mathrm{a}}$, Jakub JURASZ ${ }^{\mathrm{b}}$, Rajmund SKOWRON ${ }^{\mathrm{a}}$ \\ ${ }^{a}$ Department of Hydrology and Water Management, Nicolaus Copernicus University, \\ Lwowska 1, 87-100 Toruń, Poland \\ ${ }^{b}$ Department of Engineering Management, Faculty of Management, AGH University of Science \\ and Technology, ul. Gramatyka 10, 30-067, Kraków, Poland \\ Submitted 20 Dec. 2015; accepted 03 Mar. 2017
}

\begin{abstract}
The aim of this study is to assess the possibility of forecasting water level fluctuations in a relatively small $\left(<100 \mathrm{~km}^{2}\right)$, post-glacial lake located in a temperate climate zone by means of artificial neural networks and multiple linear regression. The area of study was Lake Serwy, located in northeastern Poland.

Two artificial neural network (ANN) multilayer perceptron (MLP) and multiple linear regression (MLR) models were built. The following explanatory variables were considered: maximal and minimal temperature (Tmax, Tmin) wind speed (WS), vertical circulation (VC) and water level from previous periods (WL). Additionally, a binary variable describing the period of the year (winter, summer) has been considered in one of the two MLP and MLR models. The forecasting models have been assessed based on selected criteria: mean absolute percentage error (MAPE), root mean squared error (RMSE), coefficient of determination (R2) and mean biased error. Considering their values and absolute deviations from observed values it was concluded that the ANN model using an additional binary variable (MLP_B+) has the best forecasting performance. Absolute deviations from observed values were the determining factor which made this model the most efficient. In the case of the MLP_B+ model, those values were about 10\% lower than in other models.

The conducted analyses indicated good performance of ANN networks as a forecasting tool for relatively small lakes located in temperate climate zones. It is acknowledged that they enable water level forecasting with greater precision and lower absolute deviations than the use of multiple linear regression models.
\end{abstract}

Keywords: ANN, multiple linear regression, lake Serwy, water level, post-glacial lake.

\section{Introduction}

Lakes are very sensitive parts of the environment, responding very quickly to changes in inflow water volume. Hence, systematic measurement of their water level allows knowledge of the range of seasonal and long-term variations in inflow and outflow to be gathered. They may also indirectly be a source of information on transformations in water balance, or regional climate changes (Hartmann 1990; Angel, Kunkel 2010).

Information regarding water level fluctuations is essential in coastal zone management, for the location both of water management facilities (inter alia potable water intakes) and of tourism/recreation (beaches, decks, educational trails). Water level changes determine the vegetation and occurrence of certain kinds of plant life that will flourish along a coastal zone (Nicol, Ganf 2000; Riis, Hawes 2002). The impact of water level regime on the development of different plant communities has been demonstrated experimentally (Weiher, Keddy 1995; Nielsen, Chick 1997).

The ability to accurately forecast water level changes in lakes enables conducting of a well thought-out water management within given area or catchment. Additionally it indirectly provides information on the volume of water resources which is of great importance in case of energy generation and irrigation. Precise forecasts makes evidencing and detection of variation in water ecosystem functioning much easier and enable faster adjustments to those changes. 
As part of the water ecosystem of a given area, lakes are influenced by a number of natural and anthropogenic factors. Human activities manifest themselves as interference in the volume and velocity of water outflow from the drainage basin. In the case of natural factors, the basic determinant shaping water conditions is climate. All attempts to model the lake water level must be preceded by an in-depth local analysis of the lake and its catchment in order to properly identify all explanatory variables. At the same time, it is important to note that it may be an arduous or even impossible task to take into consideration all factors influencing water level fluctuations. The best example of a reason for this is miscellaneous human interference in the water resources of a given area: these activities are often not registered, and are hard to specify and take into account in any model. Therefore, it is important to consider in the future application of any model created, that some explanatory variables have not been considered.

So far in papers focusing on water level fluctuations, authors have considered diverse sets of hydrological and hydro-meteorological parameters (Bengtsson, Malm 1997; Jones et al. 2001). The most commonly used explanatory variables include (Talebizadeh, Moridnejad 2011):

- inflow and outflow rates;

- historical time series of water levels;

- sum of precipitation over a given period;

- evaporation;

- wind speed;

- humidity;

- temperature.

In practice, several methods and statistical tools are used to forecast water level fluctuations. One of the most commonly used is Auto Regressive Moving Average (ARMA). It has been used by (Wiche, Vecchia 1995) in the case of Devils Lake, USA. A modified version of ARMA (ARIMA) has been successfully applied by Irvine and Eberhard (1992) for Lakes Erie and Ontario. Another approach has been implemented by Sen et al. (2000) to model the water level of Lake Van, situated in eastern Turkey - the authors of that study used Fourier transformations combined with second-order Markov chains. One of the newer approaches in the area of water level forecasting is Artificial Neural Networks (Ondimu, Murase 2007; Çimen, Kisi 2009; Coulibaly 2010). So far, research has focused on lakes of greater than several thousand square kilometres, or those located in warm climate zones. With their ability to forecast the variability of a given time series with determined accuracy, ANNs have been used multiple times to provide broad models of water resources. As an example, they were effectively used for modelling drainage of rainwater (Shamseldin 1997; Sajikumar, Thandaveswara 1999), predicting flow (Clair, Ehrman 1998; Campolo et al. 1999; Zealand et al. 1999), forecasting groundwater level (Chełmicki et al. 2003; Daliakopoulos et al. 2005;
Nayak et al. 2006; Yang et al. 2009; Adamowski, Chan 2011), proglacial discharge simulation (Nowak, Sobota 2015) and also in issues related to water management in cities (Jain et al. 2001; Muleta, Nicklow 2005; Herrera et al. 2010; Campisi-Pinto et al. 2012).

The aim of this study is to compare the accuracy of water level forecasts based on artificial neural networks and multiple linear regression for a relatively small, postglacial lake located in a temperate climate zone. The main limitations of this study is the fact that it concentrates on only one lake (due to the data availability) and some potentially influencing factors impacting water level - such as snow cover has been neglected (due to the data availability) but mentioned. What is more this study compares only two commonly used forecasting methods but the obtained results build foundation for further research.

\section{Area of study}

The object of this study was Lake Serwy in northeastern Poland, which, similarly to most of the lakes located in the Central European Lowlands, originated during the recent Baltic Glaciation (Fig. 1).

The selection of this lake is supported by following arguments. The meteorological and hydrological measurements (in a form of time series) are taken by a meteorological station which is located not far from Lake Serwy. What is also important, those time series encompass relatively long time period and do not exhibit any missing records. Additionally morphometric parameters of the Lake Serwy make this particular lake representative for this part of Europe. Finally there is no recorded significant impact of anthropogenic factors on water level fluctuations in this lake.

In terms of area and volume, the analyzed lake is relatively large with regard to other lakes in this area. The lake has three islands, whose surfaces amount to $0.12 \mathrm{~km}^{2}$. The basic morphometric parameters are presented in Table 1.

Table 1. Morphometric parameters of Lake Serwy which enable its comparison with other lakes in this area

\begin{tabular}{lcc}
\hline \multicolumn{1}{c}{ Parameter } & Value & Unit \\
\hline Area $(\mathrm{A})$ & 4.6 & $\mathrm{~km}^{2}$ \\
\hline Volume $(\mathrm{V})$ & $67.1 \cdot 10^{6}$ & $\mathrm{~m}^{3}$ \\
\hline Maximal length $\left(\mathrm{L}_{\max }\right)$ & 6900 & $\mathrm{~m}$ \\
\hline Maximal width $\left(\mathrm{W}_{\max }\right)$ & 1100 & $\mathrm{~m}$ \\
\hline Extension $\left(\lambda=\mathrm{L}_{\max } / \mathrm{W}_{\max }\right)$ & 6.2 & - \\
\hline Mean width $\left(\mathrm{W}_{\operatorname{mean}}=\mathrm{A} / \mathrm{L}_{\max }\right)$ & 667 & $\mathrm{~m}$ \\
\hline Shoreline length $(\mathrm{SL})$ & 16100 & $\mathrm{~m}$ \\
\hline Maximal depth $\left(\mathrm{H}_{\max }\right)$ & 41.5 & $\mathrm{~m}$ \\
\hline Mean depth $\left(\mathrm{H}_{\text {mean }}=\mathrm{V} / \mathrm{A}\right)$ & 14.1 & $\mathrm{~m}$ \\
\hline
\end{tabular}


The lake is supplied with water from several small watercourses and ditches draining the surrounding marshes and wetlands. The remaining water supply sources are: direct precipitation, surface runoff from own catchment, and underground inflow. The last of these water supplies seems to be of particular significance in the case of the analyzed lake because of its considerable depth. The catchment area amounts to $53.9 \mathrm{~km}^{2}$. Forests (mainly coniferous) cover $79 \%$ of its area, the remainder consists of agricultural land (farmlands and pastures). A small drainage channel is located in the southern part of the lake.

The climatic conditions of this area are typical of a temperate maritime/continental climate with significant influence of continentalism, which manifests itself in very low winter air temperatures, often exceeding $-20^{\circ} \mathrm{C}$. Subzero mean monthly temperatures occur from December to February, but also frequently in March in many years. The annual mean temperature does not exceed $7{ }^{\circ} \mathrm{C}$ and the annual sum of precipitation is $586 \mathrm{~mm}$ (Fig. 2). Precipitation occurs mainly in summer (June-August).

The highest water level is usually observed during spring (April-May). In the subsequent months the water level tends to decline as a result of intensified evaporation. In September and October the water level reaches its nadir (Fig. 3). Over the analyzed period the annual water level amplitude reached $42 \mathrm{~cm}$.
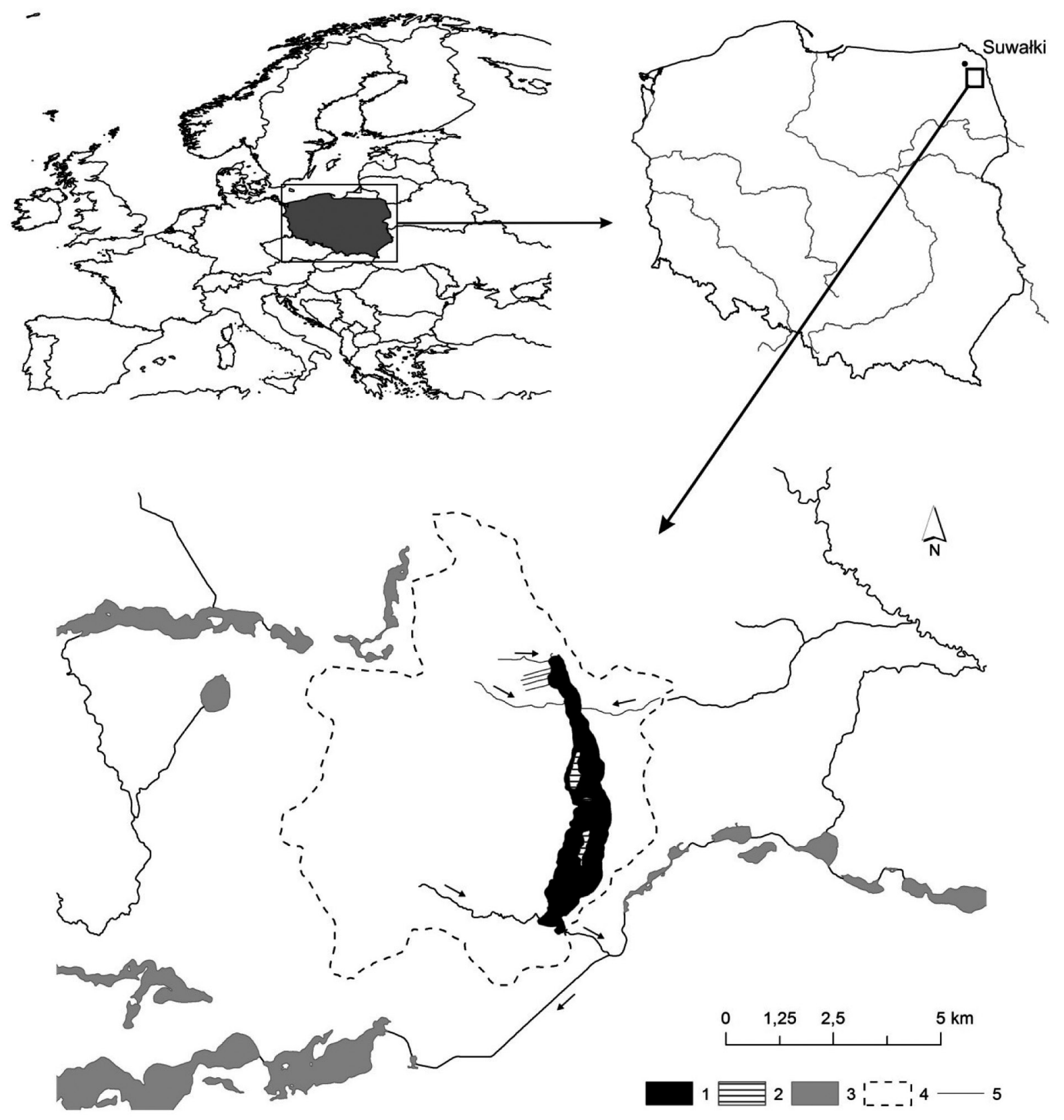

Fig. 1. Lake Serwy location from the perspective of the map of Europe and Poland. Key: 1 - Lake Serwy; 2 - islands; 3 other lakes; 4 - Lake Serwy catchment; 5 - watercourses 
Annual water level changes over a 32-year period are as shown in Figure 4.

\section{Materials and methods}

In this study, monthly values of water level (WL) in Lake Serwy over the years 1980-2012 have been used. They have been calculated based on daily observations conducted by the Institute of Meteorology and Water Management: State Research Institute (IMGW-PIB). Preliminarily, the following meteorological parameters have

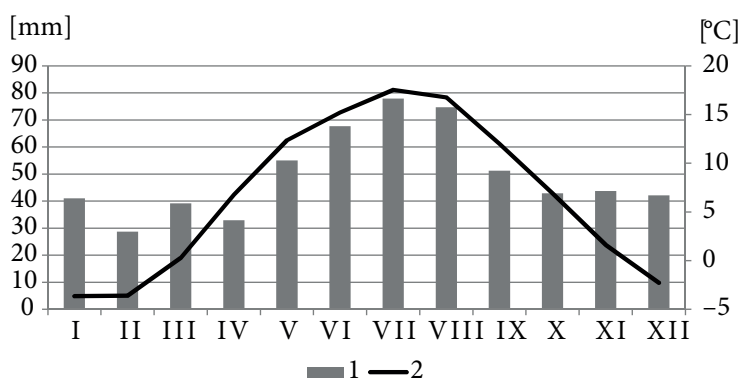

Fig. 2. Monthly sums of precipitation and monthly mean temperatures observed at the meteorological station in Suwałki over the period 1980-2012. Key: 1 - sum of precipitation; 2 - mean air temperature

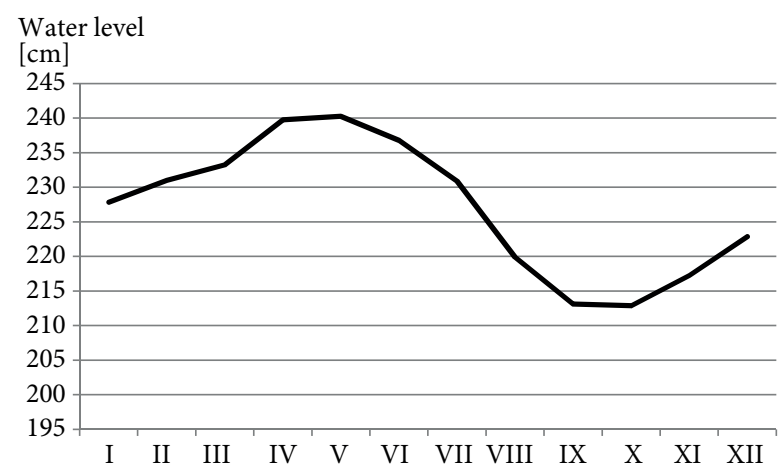

Fig. 3. Lake Serwy monthly mean water level, 1980-2012 been considered as independent variables for forecasting models:

- mean air temperature $(\mathrm{T})$;

- maximal air temperature $\left(\mathrm{T}_{\max }\right)$;

- minimal air temperature $\left(\mathrm{T}_{\min }\right)$;

- relative humidity $(\mathrm{RH})$;

- sum of rainfall - precipitation (PPT);

- wind speed (WS);

- evaporation (Evap).

Besides the above, vertical circulation (the difference between evaporation and precipitation) has also been considered. All these parameters have been observed and recorded by the meteorological station in Suwałki, which is 25 kilometres to the north of the analyzed lake. Consequently, those monthly values correspond to the same time period as the water level values.

The explanatory variables initially described above have been tested by means of a correlation coefficient, in order to determine whether they have a significant impact on water level (Tables 2 and 3). Based on the calculations conducted a meaningful correlation between some of the variables has been observed. From further analyses, all those which exhibit mutual correlation have been excluded and only those presenting the highest correlation with water level were used as input variables. As a result, the following variables were used in the modeling process:

- maximal and minimal air temperature $\left(\mathrm{T}_{\max }, \mathrm{T}_{\min }\right)$;

- wind speed (WS);

- vertical circulation;

- water level from previous periods (WL).

It should be pointed out that, during the forecasting process, only explanatory variables of historical values referring to one (T-1) and two (T-2) previous months were used.

The structure of forecasting models (their architecture or formulas) is presented in Table 4. The quantitative
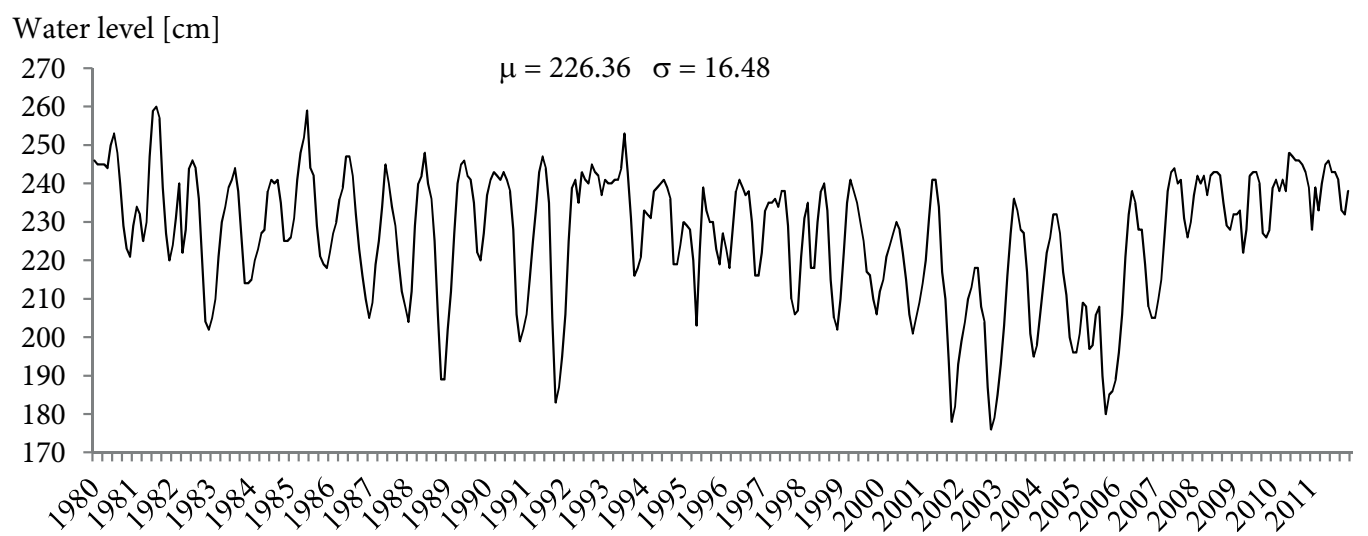

Fig. 4. Lake Serwy water level fluctuations in the years 1980-2012. Over this period the mean water level was equal to $\mu=226.36 \mathrm{~cm}$ with a standard deviation of $\sigma=16.48 \mathrm{~cm}$ 
Table 2. Coefficient of correlation matrix for one-month-lagged exogenous variables, bold font indicated correlation coefficients which exhibit statistical significance $-P$ value $<0.05$. $P P T$ stands for precipitation, whereas Temp for temperature

\begin{tabular}{lccccccccc}
\hline & $\begin{array}{c}\text { Water } \\
\text { level T-1 }\end{array}$ & $\begin{array}{c}\text { Evapo- } \\
\text { ration }\end{array}$ & Temp & $\begin{array}{c}\text { Wind } \\
\text { speed }\end{array}$ & Temp Max & Temp Min & $\begin{array}{c}\text { Relative } \\
\text { humidity }\end{array}$ & $\begin{array}{c}\text { PPT } \\
\text { Vertical } \\
\text { circulation }\end{array}$ \\
\hline Water level & $\mathbf{0 . 8 8 5}$ & $\mathbf{- 0 . 1 3 2}$ & $\mathbf{- 0 . 2 6 0}$ & $\mathbf{0 . 2 4 5}$ & $\mathbf{- 0 . 2 5 2}$ & $\mathbf{- 0 . 2 6 7}$ & 0.028 & -0.075 & 0.077 \\
\hline Water level T-1 & 1.000 & $\mathbf{0 . 1 7 7}$ & 0.006 & 0.061 & 0.021 & -0.018 & $-\mathbf{0 . 1 9 7}$ & -0.011 & $-\mathbf{0 . 1 8 0}$ \\
\hline Evaporation & $\mathbf{0 . 1 7 7}$ & 1.000 & $\mathbf{0 . 8 9 8}$ & $\mathbf{- 0 . 4 8 8}$ & $\mathbf{0 . 9 2 1}$ & $\mathbf{0 . 8 3 7}$ & $\mathbf{- 0 . 8 3 8}$ & $\mathbf{0 . 3 2 4}$ & $-\mathbf{0 . 7 5 7}$ \\
\hline Temp & 0.006 & $\mathbf{0 . 8 9 8}$ & 1.000 & $\mathbf{- 0 . 4 8 4}$ & $\mathbf{0 . 9 9 5}$ & $\mathbf{0 . 9 8 8}$ & $\mathbf{- 0 . 6 6 1}$ & $\mathbf{0 . 4 0 9}$ & $-\mathbf{0 . 5 9 7}$ \\
\hline Wind speed & 0.061 & $\mathbf{- 0 . 4 8 8}$ & $\mathbf{- 0 . 4 8 4}$ & 1.000 & $\mathbf{- 0 . 5 0 6}$ & $\mathbf{- 0 . 4 2 8}$ & $\mathbf{0 . 4 0 2}$ & -0.081 & $\mathbf{0 . 4 2 3}$ \\
\hline Temp Max & 0.021 & $\mathbf{0 . 9 2 1}$ & $\mathbf{0 . 9 9 5}$ & $\mathbf{- 0 . 5 0 6}$ & 1.000 & $\mathbf{0 . 9 7 1}$ & $\mathbf{- 0 . 7 0 7}$ & $\mathbf{0 . 3 8 2}$ & $-\mathbf{0 . 6 3 8}$ \\
\hline Temp Min & -0.018 & $\mathbf{0 . 8 3 7}$ & $\mathbf{0 . 9 8 8}$ & $\mathbf{- 0 . 4 2 8}$ & $\mathbf{0 . 9 7 1}$ & 1.000 & $\mathbf{- 0 . 5 5 7}$ & $\mathbf{0 . 4 4 4}$ & $-\mathbf{0 . 5 1 5}$ \\
\hline Relative humidity & $\mathbf{- 0 . 1 9 7}$ & $\mathbf{- 0 . 8 3 8}$ & $\mathbf{- 0 . 6 6 1}$ & $\mathbf{0 . 4 0 2}$ & $\mathbf{- 0 . 7 0 7}$ & $\mathbf{- 0 . 5 5 7}$ & 1.000 & -0.067 & $\mathbf{0 . 7 7 5}$ \\
\hline PPT & -0.011 & $\mathbf{0 . 3 2 4}$ & $\mathbf{0 . 4 0 9}$ & -0.081 & $\mathbf{0 . 3 8 2}$ & $\mathbf{0 . 4 4 4}$ & -0.067 & 1.000 & $\mathbf{0 . 3 7 4}$ \\
\hline Vertical circulation & $\mathbf{- 0 . 1 8 0}$ & $\mathbf{- 0 . 7 5 7}$ & $\mathbf{- 0 . 5 9 7}$ & $\mathbf{0 . 4 2 3}$ & $\mathbf{- 0 . 6 3 8}$ & $\mathbf{- 0 . 5 1 5}$ & $\mathbf{0 . 7 7 5}$ & $\mathbf{0 . 3 7 4}$ & 1.000 \\
\hline
\end{tabular}

Table 3. Coefficient of correlation matrix for two-month-lagged exogenous variables, bold font indicated correlation coefficients which exhibit statistical significance. Presented abbreviations are coherent with those presented in Table 2

\begin{tabular}{lccccccccc}
\hline & $\begin{array}{c}\text { Water } \\
\text { level T-2 }\end{array}$ & $\begin{array}{c}\text { Evapo- } \\
\text { ration }\end{array}$ & Temp & $\begin{array}{c}\text { Wind } \\
\text { speed }\end{array}$ & $\begin{array}{c}\text { Temp } \\
\text { Max }\end{array}$ & $\begin{array}{c}\text { Temp } \\
\text { Min }\end{array}$ & $\begin{array}{c}\text { Relative } \\
\text { humidity }\end{array}$ & $\begin{array}{c}\text { PPT } \\
\text { Vertical } \\
\text { circulation }\end{array}$ \\
\hline Water level & $\mathbf{0 . 6 5 3}$ & $\mathbf{- 0 . 4 0 6}$ & $\mathbf{- 0 . 4 7 2}$ & $\mathbf{0 . 3 6 3}$ & $\mathbf{- 0 . 4 7 3}$ & $\mathbf{- 0 . 4 6 2}$ & $\mathbf{0 . 2 4 2}$ & $-\mathbf{0 . 1 4 5}$ & $\mathbf{0 . 2 9 8}$ \\
\hline Water level T-2 & 1.000 & $\mathbf{0 . 1 7 2}$ & 0.003 & 0.073 & 0.017 & -0.021 & $-\mathbf{0 . 1 9 1}$ & -0.022 & $-\mathbf{0 . 1 8 3}$ \\
\hline Evaporation & $\mathbf{0 . 1 7 2}$ & 1.000 & $\mathbf{0 . 8 9 9}$ & $\mathbf{- 0 . 4 9 1}$ & $\mathbf{0 . 9 2 2}$ & $\mathbf{0 . 8 3 9}$ & $-\mathbf{0 . 8 3 8}$ & $\mathbf{0 . 3 1 6}$ & $-\mathbf{0 . 7 6 1}$ \\
\hline Temp & 0.003 & $\mathbf{0 . 8 9 9}$ & 1.000 & $\mathbf{- 0 . 4 8 5}$ & $\mathbf{0 . 9 9 5}$ & $\mathbf{0 . 9 8 8}$ & $\mathbf{- 0 . 6 6 3}$ & $\mathbf{0 . 4 0 5}$ & $\mathbf{- 0 . 6 0 2}$ \\
\hline Wind speed & 0.073 & $\mathbf{- 0 . 4 9 1}$ & $\mathbf{- 0 . 4 8 5}$ & 1.000 & $-\mathbf{0 . 5 0 8}$ & $\mathbf{- 0 . 4 2 9}$ & $\mathbf{0 . 4 0 9}$ & -0.084 & $\mathbf{0 . 4 2 2}$ \\
\hline Temp Max & 0.017 & $\mathbf{0 . 9 2 2}$ & $\mathbf{0 . 9 9 5}$ & $\mathbf{- 0 . 5 0 8}$ & 1.000 & $\mathbf{0 . 9 7 1}$ & $-\mathbf{0 . 7 0 9}$ & $\mathbf{0 . 3 7 8}$ & $-\mathbf{0 . 6 4 3}$ \\
\hline Temp Min & -0.021 & $\mathbf{0 . 8 3 9}$ & $\mathbf{0 . 9 8 8}$ & $\mathbf{- 0 . 4 2 9}$ & $\mathbf{0 . 9 7 1}$ & 1.000 & $-\mathbf{0 . 5 5 9}$ & $\mathbf{0 . 4 3 9}$ & $\mathbf{- 0 . 5 2 0}$ \\
\hline Relative humidity & $\mathbf{- 0 . 1 9 1}$ & $\mathbf{- 0 . 8 3 8}$ & $\mathbf{- 0 . 6 6 3}$ & $\mathbf{0 . 4 0 9}$ & $\mathbf{- 0 . 7 0 9}$ & $\mathbf{- 0 . 5 5 9}$ & 1.000 & -0.063 & $\mathbf{0 . 7 7 5}$ \\
\hline PPT & -0.022 & $\mathbf{0 . 3 1 6}$ & $\mathbf{0 . 4 0 5}$ & -0.084 & $\mathbf{0 . 3 7 8}$ & $\mathbf{0 . 4 3 9}$ & -0.063 & 1.000 & $\mathbf{0 . 3 7 5}$ \\
\hline Vertical circulation & $\mathbf{- 0 . 1 8 3}$ & $\mathbf{- 0 . 7 6 1}$ & $\mathbf{- 0 . 6 0 2}$ & $\mathbf{0 . 4 2 2}$ & $\mathbf{- 0 . 6 4 3}$ & $\mathbf{- 0 . 5 2 0}$ & $\mathbf{0 . 7 7 5}$ & $\mathbf{0 . 3 7 5}$ & 1.000 \\
\hline
\end{tabular}

Table 4. Structure, parameters and equations for MLP and MLR models. SOS stands for sum of squared error, BFGS - is a teaching algorithm and its name is an abbreviation from its developers, namely Broyden-Fletcher-Goldfarb-Shanno

\begin{tabular}{|c|c|c|c|c|c|c|c|c|}
\hline Name & Structure & $\begin{array}{l}\text { Teaching } \\
\text { quality }\end{array}$ & $\begin{array}{l}\text { Testing } \\
\text { quality }\end{array}$ & $\begin{array}{l}\text { Validation } \\
\text { quality }\end{array}$ & $\begin{array}{l}\text { Teaching } \\
\text { algorithm }\end{array}$ & $\begin{array}{c}\text { Error } \\
\text { function }\end{array}$ & $\begin{array}{l}\text { Activation } \\
\text { hidden layer }\end{array}$ & $\begin{array}{l}\text { Activation } \\
\text { output layer }\end{array}$ \\
\hline MLP_Bin+ & MLP 8-6-1 & 0.963 & 0.934 & 0.920 & BFGS 108 & SOS & Tanh & Tanh \\
\hline MLP_Bin- & MLP 7-8-1 & 0.958 & 0.917 & 0.915 & BFGS 60 & SOS & Tanh & Logistic \\
\hline MLR_Bin+ & \multicolumn{8}{|c|}{$\begin{array}{l}W L(t)=1.1985 \times W L(T-1)+1.0123 \times W S(T-1) 00.2118 \times T_{\min }(T-1)-0.361 \times W L(T-2)-0.2808 \times W S(T-2)- \\
0.06836 \times T_{\max }(T-2)+0.0091 \times C V(T-2)-0.7577 \times \operatorname{Bin}+35.8324\end{array}$} \\
\hline MLR_Bin- & \multicolumn{8}{|c|}{$\begin{array}{l}W L(t)=1.1978 \times W L(T-1)+1.1271 \times W S(T-1)-0.2647 \times T_{\min }(T-1)-0.3654 \times W L(T-1)-0.3414 \times \\
W S(T-2)-0.0357 \times T_{\text {max }}(T-2)+0.0185 \times V C(T-2)+36.1983\end{array}$} \\
\hline
\end{tabular}

Conventions: $W L$ - water level, $W S$ - wind speed, $T_{\min }$ - minimal temperature, $T_{\max }$ - maximal temperature, $V C$ - vertical circulation, $T-1$ - one-month lag, $T-2$ - two-month lag 
variables have been supplemented by one qualitative (binary) variable which refers to the winter or summer halfyear, where 1 is the summer and 0 is the winter half-year. After input variable selection, two artificial neural network MLP (Multilayer Perceptron) models and two multilinear regression equations were built. The procedure of creating ANN models have described by Dayhoff and DeLeo in (Dayhoff, DeLeo 2001) whereas MLR by Kutner et al. in (Kutner et al. 1996). The sets of quantitative variables for the MLP and MLR models are the same, but within both methods, models taking into account the binary variable (Bin+) and those not taking into account the binary variable (Bin-) have been separated. MLR and ANN models were created using Statistica 10 software.

The constructed models were assessed based on four performance measures described below. The most commonly used and easily interpreted is MAPE (mean absolute percentage error) defined as:

$$
\text { MAPE }=\left|\frac{W L(t)-\widehat{W L}(t)}{W L(t)}\right| \cdot 100 \%,
$$

where $W L(t)$ is water level measured in time $t$, and $\widehat{W L}(t)$ is the forecasted value of water level. MAPE is an important criterion for the assessment of forecasting models from the perspective of presenting their quality to people familiar with the mean values of the considered time series. This criterion cannot be used when forecasting values should be equal to zero, due to the division by zero. The perfect match exists when MAPE is 0 , but no upper value of this criterion exists. The next used performance measure was the so-called mean biased error (MBE), which indicated whether the created model expressed a tendency to over- or underestimate the values of forecasts. It has been calculated as:

$$
\mathrm{MBE}=\frac{1}{N} \sum_{t=1}^{N}(W L(t)-\widehat{W L}(t)),
$$

where $N$ is the sample size. In the case of an ideal match, and when overestimations equal underestimations the value of MBE amounts to 0 .

The next criterion was RMSE (root mean square error), which is used to assess the variance of forecast error based on error standard deviation.

$$
\mathrm{RMSE}=\sqrt{\frac{1}{N} \sum_{t=1}^{N}(W L(t)-\widehat{W L}(t))^{2}} .
$$

The last performance measure was the coefficient of determination, which ranges from 0 to 1 , and for which, values above 0.9 are perceived as very satisfactory and below 0.8 as unsatisfactory (Legates et al. 1999). It is expressed as:

$$
\mathrm{R}^{2}=1-\frac{\sigma^{2}(\hat{W}-W)}{\sigma^{2}(W)},
$$

where $\sigma^{2}$ is set variation.
Due to the particularities of the process of ANN model creation, which requires the division of time series into teaching, validating and testing subsets, MLR and MLP models have been assessed only on the basis of the testing subset.

\section{Results and discussion}

The obtained results, which are presented in Table 5, are similar for all forecasting models. The most precise forecasts were derived for an ANN model which used the additional binary variable (MLP_B+). It got the most beneficial values of MAPE, RMSE and R2 criteria, while the value of MBE did not diverge far from that of the MLR models. Similar values of individual forecasting criteria have been obtained by other researchers, despite the different characteristics of the lakes investigated (Kisi et al. 2012; Noury et al. 2014; Young 2015; Yarar et al. 2009; Vaziri 1997). This confirms the possibility of an efficient application of ANN to forecasting water level of lakes located in temperate climates (with cold winters) and having a relatively low area (under $100 \mathrm{~km}^{2}$ ).

Table 5. Values of forecasting performance measures

\begin{tabular}{lcccc}
\hline & MLR_B+ & MLR_B- & MLP_B+ & MLP_B- \\
\hline MAPE & $2.055 \%$ & $2.054 \%$ & $1.838 \%$ & $2.017 \%$ \\
\hline MBE & 0.060 & 0.061 & 0.067 & -0.245 \\
\hline RMSE & 6.654 & 6.700 & 5.706 & 6.374 \\
\hline R2 & 0.909 & 0.908 & 0.934 & 0.917 \\
\hline
\end{tabular}

The graphical representation of forecasts obtained from the four models shows an approximate congruence to the real values. In Figure 5, the values of the testing set have been sorted in increasing order, in order to depict the model's behaviour in the face of extreme values. This is not related to the trend in water level changes, which over the last 30 years has been in slight decline. Additionally, a horizontal steady line has been marked on the chart and can be used as a benchmark for the values of relative errors. The highest values of deviation from observed water level occurred in the same months. This may suggest that, in forecasting models, not all essential explanatory variables have been considered. Confirmation of this suggestion is provided by the juxtaposition of periods when those deviations were observed. The highest errors occurred during spring months, namely April and May. In this period, the Lake is heavily supplied with water stored in snow and ice sheets. In order to improve forecast quality, knowledge of ice and snow sheet cover thickness in the winter period is essential. The lack of this kind of data for the analyzed area made their application in this study impossible.

It is worth noting that, so far in papers reporting research related to the modeling and forecasting of water 
level, the issue of snow and ice sheets has gone unnoticed. The vast majority of this research concerned lakes with much greater areas and often located in warm climates. The best example here is Lake Van in Turkey, for which satisfactory forecasting performance of water level was obtained from models based only on water level values from previous periods (Altunkaynak 2007). A set of explanatory variables similar to those presented in this study, with values for: water flow in two supplying rivers (Gilgil and Malewa), evaporation, rainfall and simple time harmonics, was used in case of Lake Naivasha in Africa (Ondimu, Murase 2007).

An investigation into how individual models deal with the forecasting of extreme values appears to be of interest. In those cases, models tend very often to over- or underestimate the real values. From a testing set amounting to 57 samples, five extreme (minimal and maximal) samples were selected. The sum of relative errors among those subsets has been presented in Table 6. In both analyzed methods there is a similar tendency to overestimate
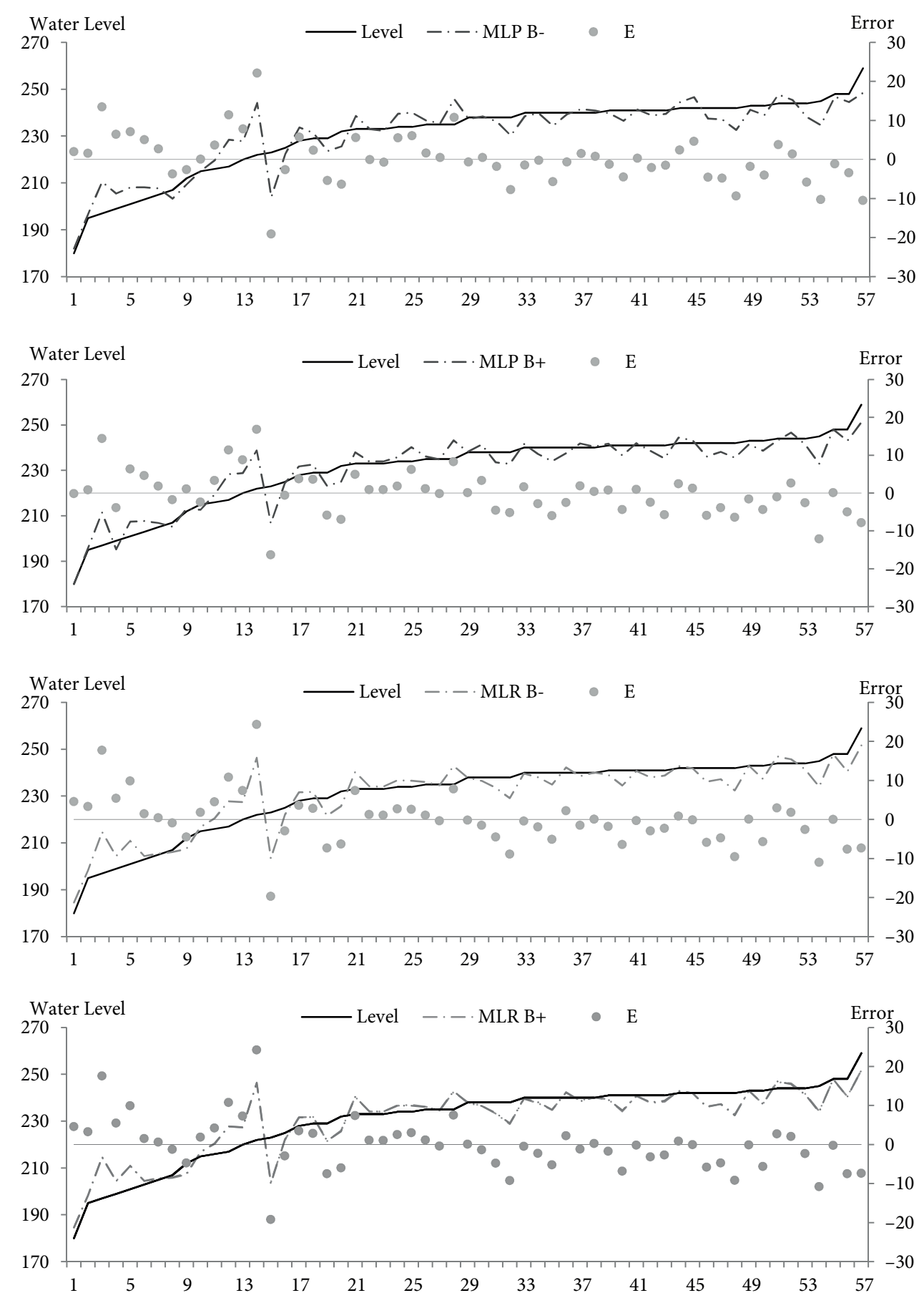

Fig. 5. Observed and forecasted values of water level for various models. Charts have been arranged from the lowest to the highest values of water level along with the forecasted water level and the value of relative errors 
the value of forecasts in the case of low water level and vice versa when the water level was high. However, in the case of low water level, the ANN model performed better, as seen in the case of the MLP_B+ model, for which the sum of relative error was over two times smaller than for the MLR models. Also worthy of note is the fact that the MLP_B- model equally under- and overestimated its forecasts. However, in the case of that model, the quality of forecasts was slightly worse than for other models. Based on this comparison, it is possible to state that for a given time series (and testing set) and for the presented input variables, the multiple linear regression models have a tendency to overestimate forecasts for extreme values. In the case of ANN models those values are smaller, and, depending on input set characteristics, they may level out.

Table 6. Sum of relative errors for extreme water level values

\begin{tabular}{lcccc}
\hline $\begin{array}{l}\text { Water } \\
\text { Level }\end{array}$ & MLR B+ & MLR B- & MLP B+ & MLP B- \\
\hline Low & 40.9 & 40.9 & 17.8 & 30.7 \\
\hline High & -28.0 & -28.4 & -27.2 & -31.1 \\
\hline
\end{tabular}

Confirmation of the better forecasting performance of MLP_B+ for extreme values is provided in Figure 6, which presents absolute values of deviation. It is important to note that only in the case of the MLP_B+ model were the obtained values smaller than $18 \mathrm{~cm}$, while in other cases they were over $24 \mathrm{~cm}$.

\section{Conclusions}

The attempt to forecast water level in a relatively small lake located in a temperate climate zone by means of MLP and MLR models gave satisfactory results. The values of selected performance measures among analyzed models were approximate and similar to those obtained by other researchers. This is of significance mainly because of the distinct climate conditions and morphological parameters of the lakes considered in all studies previous to this. Small post-glacial lakes located in the Central European Lowlands, to which Lake Serwy belongs, are far more prone to climate factors which determine water level fluctuations. In relation to this, the phenomenon of ice sheet covering lake in winter period and resulting thaw in spring has been brought to attention. Due to the lack of data concerning ice and snow cover in the given area, it was impossible to investigate and consider the additional water supply resulting from the spring thaw. In consequence, the biggest observed forecast error occurred during early spring (April-May).

Taking into consideration the selected performance measures and the absolute deviations from real values, it can be said that the best forecasts were obtained from an ANN model using the additional binary variable and denoted as MLP_B+. The determining factor in the better forecasting performance of this model was the absolute value of deviations from observed values. In the case of MLP_B+ they were much smaller than for the other models.

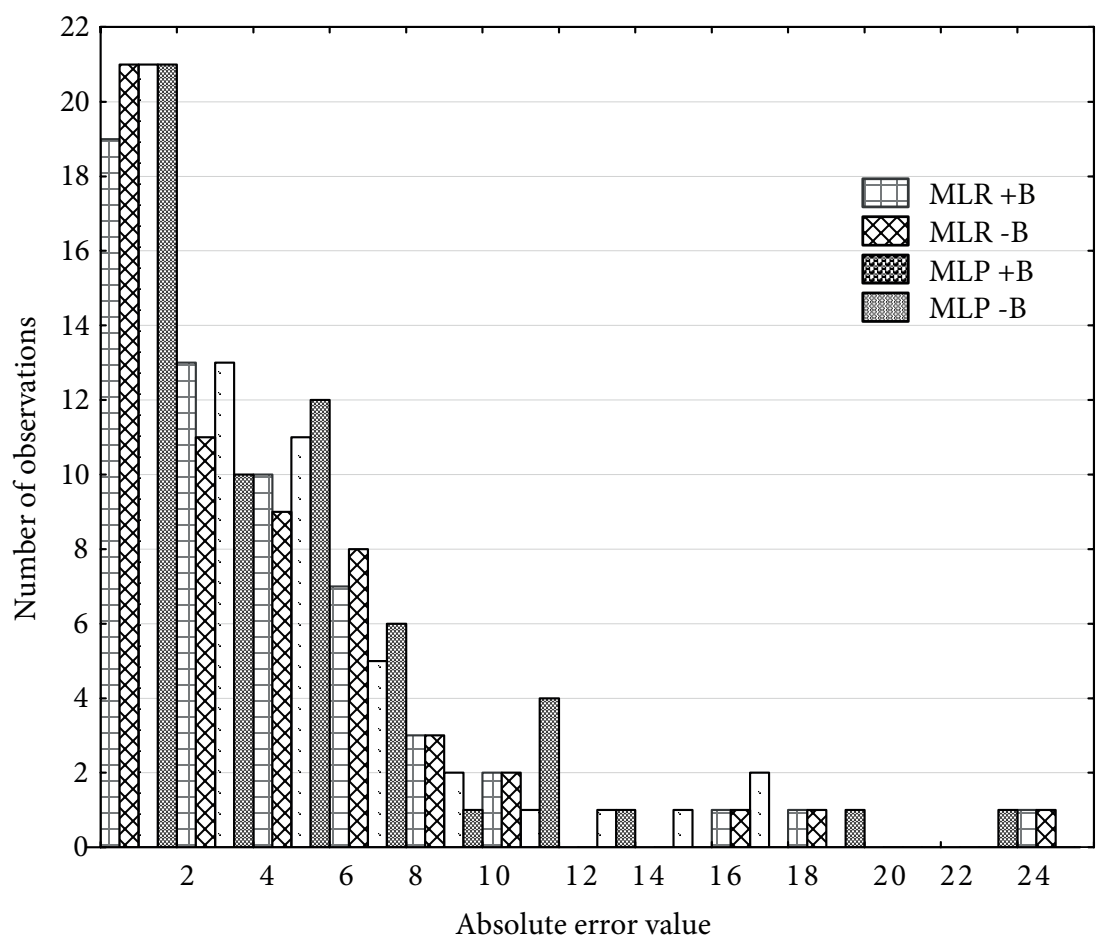

Fig. 6. Histogram of absolute errors for multi-layer perceptron (MLP) and multiple linear regression (MLR) models, with $(+B)$ and without $(-B)$ binary variable 
In conclusion, it must be said that ANN models are an efficient tool when it comes to water level fluctuation forecasting, including in the case of relatively small lakes located in temperate climate zones. Their application enables water level forecasting with greater precision and with lower maximal deviations from observed values than the use of multiple linear regression models.

Obtained results indicate several interesting directions for the future research. One should definitely try to compare results of various forecasting models applied to predict water level fluctuation for at least several lakes. Additionally it is also very important to apply other modern forecasting techniques such as those using wavelet transform or fuzzy logic.

Models and results coming from the application of the artificial neural networks in lake water level forecasting may be a crucial parameter in modelling the changes in the natural environment. Such models seems to be of great importance when it comes to investigating various scenarios of water ecosystems operation in the context of observed climate fluctuations. A majority of issues related to the environment protection, especially from the engineering perspective is based upon models and forecasts of changes occurring in the environment which are a consequence of natural and anthropogenic factors. By using artificial neural networks in area of environmental engineering one may get closer to understand the phenomena which drive certain processes like water level fluctuations. Changes in available outflow or water level have huge impact on the operation of hydropower plants in the context of the energy yield as well as their structural performance (Povilaitis, Querner 2008; Šadzevičius et al. 2013).

\section{References}

Adamowski, J.; Chan, H. F. 2011. A wavelet neural network conjunction model for groundwater level forecasting, Journal of Hydrology 407(1): 28-40.

https://doi.org/10.1016/j.jhydrol.2011.06.013

Altunkaynak, A. 2007. Forecasting surface water level fluctuations of lake van by artificial neural networks, Water Resources Management 21(2): 339-408.

https://doi.org/10.1007/s11269-006-9022-6

Angel, J. R.; Kunkel, K. E. 2010.The response of Great Lakes water levels to future climate scenarios with an emphasis on Lake Michigan-Huron, Journal of Great Lakes Research 36: 51-58. https://doi.org/10.1016/j.jglr.2009.09.006

Bengtsson, L.; Malm, J. 1997. Using rainfall-runoff modeling to interpret lake level data, Journal of Paleolimnology 18(3): 235-248. https://doi.org/10.1023/A:1007982710792

Campisi-Pinto, S.; Adamowski, J.; Oron, G. 2012. Forecasting urban water demand via wavelet-denoising and neural network models. Case study: city of Syracuse, Italy, Water Resources Management 26(12): 3539-3558.

https://doi.org/10.1007/s11269-012-0089-y
Campolo, M.; Andreussi, P.; Soldati, A. 1999. River flood forecasting with a neural network model, Water Resources Research 35(4): 1191-1197.

https://doi.org/10.1029/1998WR900086

Chełmicki, W.; Ciszewski, S.; Klimek, M.; Żelazny, M. 2003. Rekonstrukcja wahań zwierciadła wód gruntowych w Puszczy Niepołomickiej za pomocą sieci neuronowych [Reconstruction of groundwater levels in the Niepołomice Forest (S Poland) using neural network], Przegląd Geograficzny 75(2): 250-268.

Çimen, M.; Kisi, O. 2009. Comparison of two different data-driven techniques in modeling lake level fluctuations in Turkey, Journal of Hydrology 378: 253-262. https://doi.org/10.1016/j.jhydrol.2009.09.029

Clair, T. A.; Ehrman, J. M. 1998. Using neural networks to assess the influence of changing seasonal climates in modifying discharge, dissolved organic carbon, and nitrogen export in eastern Canadian rivers, Water Resources Research 34(3): 447-455. https://doi.org/10.1029/97WR03472

Coulibaly, P. 2010. Reservoir Computing approach to Great Lakes water level forecasting, Journal of Hydrology 381: 7688. https://doi.org/10.1016/j.jhydrol.2009.11.027

Daliakopoulos, I. N.; Coulibaly, P.; Tsanis, I. K. 2005. Groundwater level forecasting using artificial neural networks, Journal of Hydrology 309(1): 229-240. https://doi.org/10.1016/j.jhydrol.2004.12.001

Dayhoff, J. E.; DeLeo, J. M. 2001. Artificial neural networks, Cancer 91(S8): 1615-1635. https://doi.org/10.1002/10970142(20010415)91:8+<1615::AID-CNCR1175>3.0.CO;2-L

Hartmann, H. 1990. Climate change impacts on Laurentian Great Lakes levels, Climate Change 17: 49-67. https://doi.org/10.1007/BF00149000

Herrera, M.; Torgo, L.; Izquierdo, J.; Pérez-García, R. 2010. Predictive models for forecasting hourly urban water demand, Journal of Hydrology 387(1): 141-150. https://doi.org/10.1016/j.jhydrol.2010.04.005

Irvine, K. N.; Eberhardt, A. J. 1992. Multiplicative, seasonal ARIMA models for Lake Erie and Lake Ontario water levels, Water Resources Bulletin 28(2): 385-396. https://doi. org/10.1111/j.1752-1688.1992.tb04004.x

Jain, A.; Varshney, A. K.; Joshi, U. C. 2001. Short-term water demand forecast modelling at IIT Kanpur using artificial neural networks, Water Resources Management 15(5): 299-321. https://doi.org/10.1023/A:1014415503476

Jones, R. N.; McMahon, T. A.; Bowler, J. M. 2001. Modeling historical lake levels and recent climate change at three closed lakes. Western Victoria, Australia (c. 1840-1990), Journal of Hydrology 246(1-4): 159-180. https://doi.org/10.1016/S0022-1694(01)00369-9

Kisi, O.; Shiri, J.; Nikoofar, B. 2012. Forecasting daily lake levels using artificial intelligence approaches, Computers \& Geosciences 41: 169-180. https://doi.org/10.1016/j.cageo.2011.08.027

Kutner, M. H.; Neter, J.; Wasserman, W.; Nachtsheim, C. 1996. Applied linear statistical models. Chicago: Irwin.

Legates, D. R.; Gregory, J.; McCabe, Jr. 1999. Evaluating the use of "goodness-of-fit" measures in hydrologic and hydroclimatic model validation, Water Resources Research 35(1): 233-241. https://doi.org/10.1029/1998WR900018 
Muleta, M. K.; Nicklow, J. W. 2005. Decision support for watershed management using evolutionary algorithms, Journal of Water Resources Planning and Management 131(35): 35-44. https://doi.org/10.1061/(ASCE)0733-9496(2005)131:1(35)

Nayak, P. C.; Rao, Y. S.; Sudheer, K. P. 2006. Groundwater level forecasting in a shallow aquifer using artificial neural network approach, Water Resources Management 20(1): 77-90. https://doi.org/10.1007/s11269-006-4007-z

Nicol, J. M.; Ganf, G. G. 2000.Water regimes, seedling recruitment and establishment in three wetland plant species, $M a$ rine and Freshwater Research 51(4): 305-309. https://doi.org/10.1071/MF99147

Nielsen, D. L.; Chick, A. J. 1997. Flood-mediated changes in aquatic macrophyte community structure, Marine and Freshwater Research 48: 153-157. https://doi.org/10.1071/MF96090

Noury, M.; Sedghi, H.; Babazedeh, H.; Fahmi, H. 2014. Urmia lake water level fluctuation hydro informatics modeling using support vector machine and conjunction of wavelet and neural network, Water Resources 41(3): 261-269. https://doi.org/10.1134/S0097807814030129

Nowak, M.; Sobota, I. 2015. Artificial neural networks in proglacial discharge simulation: application and efficiency analysis in comparison to the multivariate regression; a case study of Waldemar River (Svalbard), Geografiska Annaler: Series A, Physical Geography 97(3): 489-506. https://doi.org/10.1111/geoa.12089

Ondimu, S.; Murase, H. 2007. Reservoir level forecasting using neural networks: Lake Naivasha, Biosystems Engineering 96(1): 135-138.

https://doi.org/10.1016/j.biosystemseng.2006.09.003

Povilaitis, A.; Querner, E.P. 2008. Possibilities to restore natural water regime in the Žuvintas Lake and surrounding wetlands - modelling analysis approach, Journal of Environmental Engineering and Landscape Management 16(3): 105-112. https://doi.org/10.3846/1648-6897.2008.16.105-112

Riis, T.; Hawes, I. 2002. Relationships between water level fluctuations and vegetation diversity in shallow water of New Zealand lakes, Aquatic Botany 74: 133-148. https://doi.org/10.1016/S0304-3770(02)00074-8

Šadzevičius, R.; Damulevičius, V:; Skominas, R. 2013. The technical state of earth dams in Lithuania, Journal of Environmental Engineering and Landscape Management 21(3): 180-188. https://doi.org/10.3846/16486897.2012.662910
Sajikumar, N.; Thandaveswara, B. S. 1999. A non-linear rainfallrunoff model using an artificial neural network, Journal of Hydrology 216(1): 32-55. https://doi.org/10.1016/S0022-1694(98)00273-X

Şen, Z.; Kadioğlu, M.; Batur, E. 2000. Stochastic modeling of the Van Lake monthly level fluctuations in Turkey, Theoretical and Applied Climatology 65(1-2): 99-110. https://doi.org/10.1007/s007040050007

Shamseldin, A. Y. 1997. Application of a neural network technique to rainfall-runoff modeling, Journal of Hydrology 199(3): 272-294. https://doi.org/10.1016/S0022-1694(96)03330-6

Talebizadeh, M.; Moridnejad, A. 2011. Uncertainty analysis for the forecast of lake level fluctuations using ensembles of ANN and ANFIS models, Expert Systems with Applications 38(4): 4126-4135. https://doi.org/10.1016/j.eswa.2010.09.075

Vaziri, M. 1997. Predicting Caspian Sea surface water level by ANN and ARIMA models, Journal of Waterway, Port, Coastal, and Ocean Engineering 123(4): 158-162. https://doi.org/10.1061/(ASCE)0733-950X(1997)123:4(158)

Weiher, E.; Keddy, P. A. 1995. The assembly of experimental wetland plant communities, Oikos 73: 323-335. https://doi.org/10.2307/3545956

Wiche, G. J.; Vecchia, A. V. 1995. Lake-level frequency analysis for Devils Lake, North Dakota [online], [cited 10 January 2016]. Available from Internet: https://pubs.er.usgs.gov/publication/ ofr 95123

Young, C.-C.; Liu, W.-C.; Hsieh, W.-L. 2015. Predicting the water level fluctuation in an Alpine Lake using physically based, artificial neural network, and time series forecasting models, Mathematical Problems in Engineering. Article ID 708204. https://doi.org/10.1155/2015/708204

Yang, Z. P.; Lu, W. X.; Long, Y. Q.; Li, P. 2009. Application and comparison of two prediction models for groundwater levels: a case study in Western Jilin Province, China, Journal of Arid Environments 73(4): 487-492. https://doi.org/10.1016/j.jaridenv.2008.11.008

Yarar, A.; Onucyildiz, M.; Copty, N. K. 2009. Modelling level change in lakes using neuro-fuzzy and artificial neural networks, Journal of Hydrology 365(3-4): 329-334. https://doi.org/10.1016/j.jhydrol.2008.12.006

Zealand, C. M.; Burn, D. H.; Simonovic, S. P. 1999. Short term streamflow forecasting using artificial neural networks, Journal of Hydrology 214(1): 32-48.

https://doi.org/10.1016/S0022-1694(98)00242-X

\begin{abstract}
Adam PIASECKI. Mr. Adam Piasecki (MSc) is a PhD student at the Nicolaus Copernicus University in Toruń as well as at the AGH University in Cracow. Currently he is conducting research in area of hydrology and water management. He was a participant of several national and international workshops and conferences as well as author and co-author of many scientific publications.
\end{abstract}

Jakub JURASZ. Mr. Jakub Jurasz (PhD Eng.) is a research assistant at the AGH University in Cracow. His current research concentrates on the concept of water - energy nexus as well as integration of renewable energy sources to the national power system. Dr Jurasz is an author and co-author of several dozen papers which were published in recognized journals in field of energy.

Rajmund SKOWRON. Mr. Rajmund Skowron (PhD, DSc) is an expert in are of earth sciences. Lifelong research employee of the Nicolaus Copernicus University in Toruń. His research concentrates on limnology as well as the impact of human activities on the natural environment. In his publications he investigates the problem of water temperature as well as glaciation. He was author and co-author of at least 75 scientific contributions from which majority relates physical limnology. Currently he is working on lakes disappearance in Poland as well as long long-term changes in lakes thermal regime. 